\title{
openheart Investigating the efficacy of chest pressure for direct current cardioversion in atrial fibrillation: a randomised control trial protocol (Pressure-AF)
}

David Ferreira ${ }^{10},{ }^{1,2}$ Philo Mikhail, ${ }^{3}$ Michael McGee, ${ }^{2,4}$ Andrew Boyle, ${ }^{1,2,5}$
Aaron Sverdlov, ${ }^{1,2,5}$ Maged William, ${ }^{3}$ Nicholas Jackson, ${ }^{1}$ Malcolm Barlow, ${ }^{1}$
James Leitch, ${ }^{1}$ Nicholas Collins,,${ }^{1,2,5}$ Thomas Ford $10,{ }^{2,3}$ Bradley Wilsmore ${ }^{1}$

\section{ABSTRACT}

- Additional supplemental material is published online only. To view, please visit the journal online (http://dx.doi.org/10. 1136/openhrt-2021-001739).

To cite: Ferreira D, Mikhail $P$, McGee M, et al. Investigating the efficacy of chest pressure for direct current cardioversion in atrial fibrillation: a randomised control trial protocol (PressureAF). Open Heart

2021;8:e001739. doi:10.1136/ openhrt-2021-001739

Received 29 May 2021 Accepted 27 August 2021

A) Check for updates

(c) Author(s) (or their employer(s)) 2021. Re-use permitted under CC BY-NC. No commercial re-use. See rights and permissions. Published by BMJ.

For numbered affiliations see end of article.

Correspondence to Dr David Ferreira; david. ferreira@health.nsw.gov.au
Introduction Atrial fibrillation (AF) is the most common sustained arrhythmia worldwide. Direct current cardioversion is commonly used to restore sinus rhythm in patients with AF. Chest pressure may improve cardioversion success through decreasing transthoracic impedance and increasing cardiac energy delivery. We aim to assess the efficacy and safety of routine chest pressure with direct current cardioversion for AF.

Methods and analysis Multicentre, double blind (patient and outcome assessment), randomised clinical trial based in New South Wales, Australia. Patients will be randomised $1: 1$ to control and interventional arms. The control group will receive four sequential biphasic shocks of $150 \mathrm{~J}, 200$ $\mathrm{J}, 360 \mathrm{~J}$ and $360 \mathrm{~J}$ with chest pressure on the last shock, until cardioversion success. The intervention group will receive the same shocks with chest pressure from the first defibrillation. Pads will be placed in an anteroposterior position. Success of cardioversion will be defined as sinus rhythm at $1 \mathrm{~min}$ after shock. The primary outcome will be total energy provided. Secondary outcomes will be success of first shock to achieve cardioversion, transthoracic impedance and sinus rhythm at post cardioversion ECG.

Ethics and dissemination Ethics approval has been confirmed at all participating sites via the Research Ethics Governance Information System. The trial has been registered on the Australia New Zealand Clinical Trials Registry (ACTRN12620001028998). De-identified patient level data will be available to reputable researchers who provide sound analysis proposals.

\section{INTRODUCTION}

Atrial fibrillation (AF) is the most common persistent arrythmia worldwide and a significant contributor to poor quality of life. ${ }^{12}$ Currently, there are an estimated 37 million individuals with AF globally. Projections to the year 2050 indicate a $60 \%$ absolute increase in AF prevalence. ${ }^{3}$ Given the huge burden of disease, measures to prevent and optimally treat $\mathrm{AF}$ are of great importance.
Recently, there has been renewed interest in the benefit of rhythm control in those with $\mathrm{AF}^{4}{ }^{4}$ Direct current cardioversion is an elective procedure commonly used to terminate arrhythmias and plays an important role in rhythm control for AF.

\section{Rhythm control for AF}

Initial trials comparing rate and rhythm control for AF showed no difference in outcomes, and perhaps increased hospitalisations with rhythm control. ${ }^{56}$ Despite this, recent trials have shown benefit to rhythm control in select populations. In those with heart failure with reduced ejection fraction and persistent ventricular dysfunction despite medical therapy, mortality reduction is seen with catheter ablation. ${ }^{78}$ Moreover, in younger patients with early AF, there may be small improvements in cardiovascular endpoints with rhythm control. ${ }^{7}$ Clearly, a tailored approach to AF management is needed. Therapeutic strategies are dependent on patient preference, symptoms, the presence of structural heart disease and risks associated with interventions.

In those whom rhythm control is felt to be appropriate, electrical cardioversion offers a promising means of restoring sinus rhythm. The limitation of electrical cardioversion is that initial restoration of sinus rhythm does not ensure maintenance of sinus rhythm. Patients generally also require longer term antiarrhythmic therapy and lifestyle modification. Early success of cardioversion for $\mathrm{AF}$ was low, around $75 \% .{ }^{9}$ Over the past decades, numerous techniques have been implemented to improve restoration of sinus rhythm. With these methods, sinus rhythm is achieved in over $90 \%$ of cases. ${ }^{10}$ 


\begin{tabular}{ll}
\hline $\begin{array}{l}\text { Table } 1 \quad \text { Clinician-controlled modifiers that increase } \\
\text { cardioversion success }\end{array}$ \\
\hline $\begin{array}{l}\text { Clinician-controlled } \\
\text { modifiers of success }\end{array}$ & Proposed mechanism \\
\hline $\begin{array}{l}\text { Energy intensity (joules provided) } \\
\text { Form of energy (biphasic vs } \\
\text { monophasic) }\end{array}$ & Increased cardiac energy delivery \\
$\begin{array}{l}\text { Pad position (anterolateral vs } \\
\text { anteroposterior) }\end{array}$ & Increasing atrial energy delivery \\
$\begin{array}{l}\text { Chest pressure (placed on the } \\
\text { anterior pad) }\end{array}$ & $\begin{array}{l}\text { Decreased transthoracic } \\
\text { impedance }\end{array}$ \\
\hline
\end{tabular}

\section{Cardioversion techniques to improve success}

Chance of successful cardioversion is directly proportional to cardiac energy delivery. Increased energy delivery heightens the chance of simultaneous depolarisation of all cardiac tissue. ${ }^{11} 12$ There are four major clinician-controlled modifiers that can increase cardiac energy delivery (see table 1). The first is the intensity of energy provided during cardioversion. While other arrythmias require less energy, $50-100 \mathrm{~J}$ for atrial flutter, for example, the electrical disorganisation of $\mathrm{AF}$ requires higher energies. International guidelines recommend initiating treatment at $150-200 \mathrm{~J} .{ }^{13}$ The second variable is defibrillator pad position. Anteroposterior pad placement seems to improve success compared with anterolateral positioning. ${ }^{14}$ The mechanism may be through increased atrial energy delivery. The third variable is the energy form delivered. Biphasic energy is more effective than monophasic energy and has been consistently shown to improve cardioversion success. ${ }^{15}$ The final modifier is the provision of chest pressure during cardioversion. Chest pressure appears efficacious through reducing transthoracic impedance which is inversely proportional to cardiac energy delivery. ${ }^{16}$

\section{Risks of electrical cardioversion}

While increasing energy will improve cardioversion success, this is also associated with risk. Moderate to severe post procedural chest pain is reported to occur in $23 \%$ of cases and is directly proportional to energy delivery. ${ }^{17}$ Cutaneous burns are another significant complication of cardioversion and often associated with high energy shocks. ${ }^{18}$ Measures to reduce energy requirements, while maintaining cardioversion efficacy, have the potential benefits of decreasing patient discomfort and reducing burn incidence.

\section{Chest pressure with cardioversion}

While chest pressure during cardioversion is reproducible, simple and associated with minimal cost, there is little evidence for its use. Most clinicians still regard close patient contact during cardioversion to be unsafe to the bystander. A systematic review investigating bystander adverse events during defibrillation showed that events were uncommon, always minor and often associated with inappropriate defibrillator use. ${ }^{19}$ Moreover, a recent single centre randomised trial involving only 100 patients demonstrated no bystander adverse events with chest pressure during cardioversion. ${ }^{20}$ This trial used starting energies of $50 \mathrm{~J}$ and found improved cardioversion success, reduced shocks and reduced energy requirements with active compression. There is a clear need for external validity in an adequately powered multicentre randomised trial to examine the utility of routine chest pressure.

\section{Hypothesis and aims}

In this trial, we hypothesise that upfront manual chest pressure will reduce energy required for cardioversion and be safe for both patient and proceduralist. Moreover, we hypothesise that upfront chest pressure will increase the rate of first shock success. We aim to assess the efficacy and safety of manual chest pressure in AF with direct current cardioversion.

\section{METHODS AND ANALYSIS \\ Trial design}

This will be a prospective multicentre randomised control trial located in Australia. Patients and statistical analysis will be blinded. Inclusion criteria are age over 18 years, $\mathrm{AF}$ referred for cardioversion and 3 weeks of therapeutic anticoagulation or transoesophageal echocardiography excluding left atrial appendage thrombus (see box 1). ${ }^{21}$ Exclusion criteria are other atrial arrhythmias (atrial flutter or atrial tachycardia), those who are pregnant or breast feeding and medical comorbidity where anticoagulation is contraindicated. Definition of successful cardioversion will be sinus rhythm at 1 min after shock to maintain consistency with other studies. ${ }^{22}$ Patients will be randomised via an online tool in a 1:1 ratio to control and interventional arms.

\section{Cardioversion technique}

Anteroposterior placement of self-adhesive pads with biphasic energy will be provided to all patients. Sedation will be performed by an anaesthetist with a recommended anaesthetic regime of weight-based dosing of propofol \pm midazolam titrated to effect. Direct chest pressure will be provided on the anterior defibrillator pad with plastic gloves and a folded towel (see figure 1). Estimated chest pressure provision was assessed among cardiology advanced trainees at the centres involved. Four trainees provided 36 applications of blinded simulated chest pressure on weight scales with mean pressure of $25.5 \pm 2.6 \mathrm{~kg}$.

The control arm will receive four sequential shocks until cardioversion success with energies of 150, 200, 360 and $360 \mathrm{~J}$. Chest pressure will be provided with the final shock if the arrhythmia is refractory to the first three defibrillations. The interventional arm will receive chest pressure from the first shock with the same energies. Both arms will receive maximal energy with chest pressure (figure 2). 


\section{Box 1 Eligibility criteria}

\section{Inclusion criteria}

- Age over 18 years of age

- Ability to provide written informed consent.

- Atrial fibrillation referred for cardioversion.

- Three weeks of therapeutic anticoagulation.

- Transesophageal echocardiography excluding left atrial appendage thrombus.

Exclusion criteria

- Other atrial arrhythmias (atrial tachycardia, atrial flutter).

- Pregnant or breast feeding.

Medical comorbidity where anticoagulation is contraindicated.

\section{Primary and secondary endpoints}

The primary efficacy endpoint will be total joules provided during the cardioversion encounter. Secondary efficacy endpoints will be success of first shock for reversion to sinus rhythm, transthoracic impedance at the time of shock and sinus rhythm at post cardioversion ECG (30 min after). Safety and tolerability endpoints will be patient chest pain post cardioversion (Ordinal Scale $0-10)$ and incidence of shock delivered to proceduralist.

\section{Sample size and power calculation}

Power calculation was performed based on a retrospective analysis of direct current cardioversions over the prior year. The mean energy provided per encounter for cardioversion in AF was $280 \pm 188 \mathrm{~J}$. Assuming a mean reduction of $60 \mathrm{~J}$ in energy in the intervention group (approximately one-third of the SD), a total of 308 patients would be required for an alpha of 0.05 and power of $80 \%$. An interim analysis will be performed at 12 months to ensure adequate recruitment (at least $30 \%$ of the target) and no safety signals. Trial recruitment has begun, and 11 patients have been enrolled.

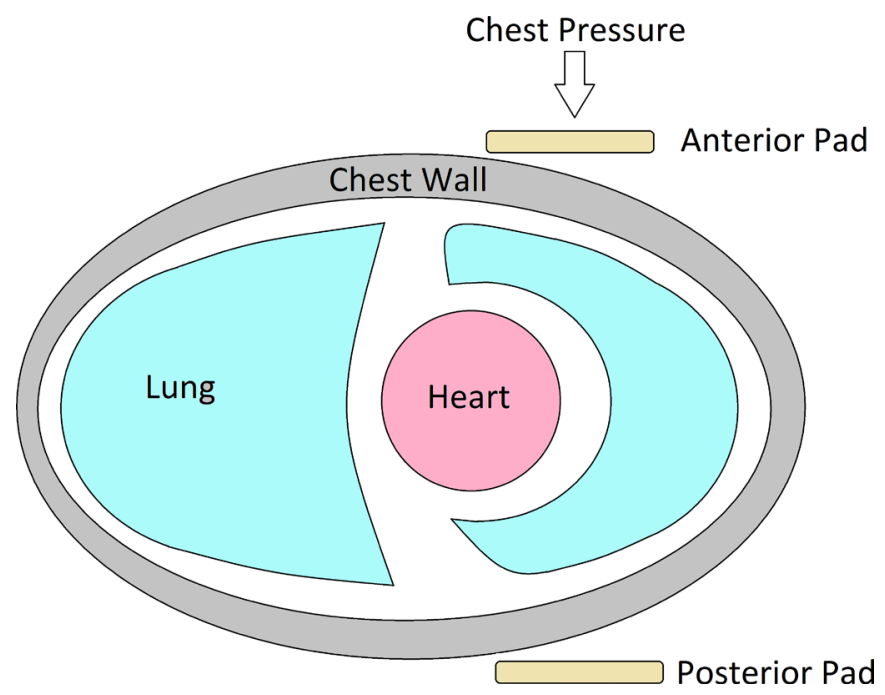

Figure 1 Diagram of cardioversion technique.

\section{Statistical analysis}

Continuous variables will be reported as mean $\pm \mathrm{SD}$ or as median and percentiles. Normally distributed variables will be compared using the paired Student's t-test. Otherwise, comparisons between both the groups will be performed using the Mann-Whitney $U$ test. Categorical variables will be stated as absolute and relative frequencies and compared using the $\chi^{2}$ test. All tests are two-tailed. A $p$ value of $<0.05$ will be considered statistically significant. Pre-specified post hoc analyses will be performed based on body mass index, left atrial size, age, antiarrhythmic therapy and duration of AF (online supplemental file 1).

\section{ETHICS AND DISSEMINATION}

Ethics approval has been confirmed at all participating sites via the Research Ethics Governance Information System. The trial has been registered on the Australia New Zealand Clinical Trials Registry (ACTRN12620001028998). In the spirit of integrity and openness, de-identified patient level data will be available to reputable researchers who provide methodologically sound proposals for analysis.

\section{DISCUSSION}

Chest pressure is a simple intervention which may be effective in reducing cardioversion energy requirements and improving cardioversion success. A small randomised trial investigated chest pressure in cardioversion for $\mathrm{AF}$ and found reduced energy requirements and improved cardioversion success. ${ }^{20}$ This trial had a sample size of 100 patients and defibrillation energy started at $50 \mathrm{~J}$. In our study, we aim to perform this multicentre study using guideline-directed energies $(150 \mathrm{~J})^{13}$ with adequately large sample size powered to definitively answer this important clinical question.

Consideration was made to quantify and standardise chest pressure provision during cardioversion in this trial. There were two main reasons why this was not pursued. First, one major benefit of chest pressure is its simplicity. External validity would be diminished if complex measures were taken to standardise chest pressure. Second, the degree of chest pressure is highly variable and depends on the body habitus of the patient. Having a 'one size fits all' approach to chest pressure provision is unlikely to be advantageous to the individual.

A theoretical concern is that of a shock being sustained by the proceduralist performing manual pressure. Despite this, a systematic review investigating bystander adverse events during defibrillation showed that events were uncommon and minor. ${ }^{19}$ At our centres, under controlled circumstances with trained staff, chest pressure has not been associated with adverse events to the proceduralist. This trial will provide quality data around the safety of manual chest pressure during defibrillation. 


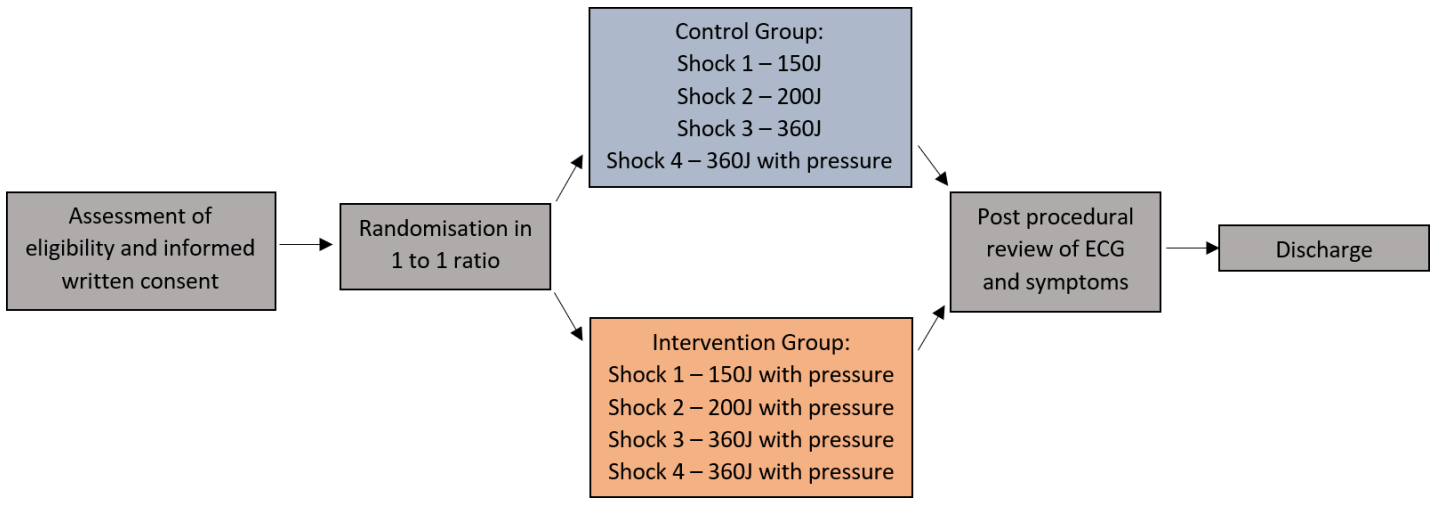

Figure 2 Day of cardioversion: study flow diagram.

Improving success of direct current cardioversion in a reproducible, cost effective and safe manner has significant implications. First, it may assist in improving symptoms in patients who suffer with symptomatic arrhythmias. Second, we may be able to provide an energy threshold by which a large proportion of patients will be successfully cardioverted with a single shock and chest pressure. Third, there are indirect implications for defibrillation during advanced life support. Manual compression when providing defibrillation to refractory shockable rhythms may improve success of resuscitation. ${ }^{23}$

In conclusion, Pressure-AF is an important clinical trial evaluating the simple intervention of chest pressure with potential to improve cardioversion success for AF.

\section{Author affiliations}

${ }^{1}$ Department of Cardiology, John Hunter Hospital, New Lambton Heights, New South Wales, Australia

${ }^{2}$ School of Medicine and Public Health, The University of Newcastle, Callaghan, New South Wales, Australia

${ }^{3}$ Department of Cardiology, Gosford Hospital, Gosford, New South Wales, Australia

${ }^{4}$ Department of Cardiology, Tamworth Rural Referral Hospital, Tamworth, New South Wales, Australia

${ }^{5}$ Hunter Medical Research Institute, Newcastle, New South Wales, Australia

\section{Twitter Aaron Sverdlov @SverdlovAaron}

Contributors DF is the coordinating primary investigator, clinical trial initiation and design, author of the first and last draft of the manuscript, clinical trial lead. PM is the primary investigator, clinical oversight at recruitment centre, data analysis, trial design and reviewer of the manuscript. MM is the primary investigator, clinical oversight at recruitment centre, data analysis, trial design and reviewer of the manuscript. $A B$ contributed to clinical trial design with speciality clinical trial experience, statistical analysis, administrative support, senior clinical oversight. AS contributed to clinical trial design with speciality clinical trial experience, statistical analysis, administrative support, senior clinical oversight. MW contributed to clinical trial design, statistical analysis, administrative support, senior clinical oversight. NJ contributed to clinical trial design with speciality electrophysiology expertise, statistical analysis, administrative support, review and editing of the manuscript. $\mathrm{MB}$ contributed to clinical trial design with speciality electrophysiology expertise, review and editing of the manuscript. $\mathrm{JL}$ contributed to clinical trial design with speciality electrophysiology expertise, review and editing of the manuscript. NC contributed to clinical trial design, contribution to manuscript authorship, project administration. TF contributed to clinical trial design, review and editing of the manuscript, senior clinical supervisor. BW is the manuscript senior author, clinical trial design, data analysis and manuscript review.

Funding AL Sverdlov is supported by the National Heart Foundation of Australia Future Leader Fellowship (award ID 101918), NSW Health Cardiovascular Capacity Building Grant and Royal Australasian College of Physicians/Foundation for High Blood Pressure (Australia) grant.

Competing interests None declared.

Patient consent for publication Not required.

Provenance and peer review Not commissioned; externally peer reviewed.

Data availability statement Data are available upon reasonable request. Deidentified patient level data will be available to reputable researchers who provide sound analysis proposals.

Open access This is an open access article distributed in accordance with the Creative Commons Attribution Non Commercial (CC BY-NC 4.0) license, which permits others to distribute, remix, adapt, build upon this work non-commercially, and license their derivative works on different terms, provided the original work is properly cited, appropriate credit is given, any changes made indicated, and the use is non-commercial. See: http://creativecommons.org/licenses/by-nc/4.0/.

\section{ORCID iDs}

David Ferreira http://orcid.org/0000-0003-3142-4503

Thomas Ford http://orcid.org/0000-0003-4009-6652

\section{REFERENCES}

1 Kornej J, Börschel CS, Benjamin EJ, et al. Epidemiology of atrial fibrillation in the 21st century. Circ Res 2020;127:4-20.

2 Schnabel RB, Pecen L, Rzayeva N, et al. Symptom burden of atrial fibrillation and its relation to interventions and outcome in Europe. $J$ Am Heart Assoc 2018;7:e007559.

3 Lippi G, Sanchis-Gomar F, Cervellin G. Global epidemiology of atrial fibrillation: an increasing epidemic and public health challenge. Int $J$ Stroke 2021:16:217-21.

4 Kirchhof P, Camm AJ, Goette A, et al. Early Rhythm-Control therapy in patients with atrial fibrillation. N Engl J Med 2020;383:1305-16.

5 Roy D, Talajic M, Nattel S, et al. Rhythm control versus rate control for atrial fibrillation and heart failure. N Engl J Med Overseas Ed 2008;358:2667-77.

6 Caldeira D, David C, Sampaio C. Rate vs rhythm control in patients with atrial fibrillation and heart failure: a systematic review and meta-analysis of randomised controlled trials. Eur J Intern Med 2011;22:448-55.

7 Marrouche NF, Brachmann J, Andresen D, et al. Catheter ablation for atrial fibrillation with heart failure. N Engl $J$ Med Overseas Ed 2018;378:417-27.

8 Di Biase L, Mohanty P, Mohanty S, et al. Ablation versus amiodarone for treatment of persistent atrial fibrillation in patients with congestive heart failure and an implanted device: results from the AATAC multicenter randomized trial. Circulation 2016;133:1637-44.

9 Frick M, Frykman V, Jensen-Urstad M, et al. Factors predicting success rate and recurrence of atrial fibrillation after first electrical cardioversion in patients with persistent atrial fibrillation. Clin Cardiol 2001;24:238-44. 
10 Alegret JM, Viñolas X, Tajes H, et al. Utility of amiodarone pretreatment as a facilitator of the acute success of electrical cardioversion in persistent atrial fibrillation. Cardiovasc Drugs Ther 2020;34:89-94.

11 Dalzell GW, Anderson J, Adgey AA. Factors determining success and energy requirements for cardioversion of atrial fibrillation. $Q J$ Med 1990;76:903-13.

12 Deale OC, Lerman BB. Intrathoracic current flow during transthoracic defibrillation in dogs. Transcardiac current fraction. Circ Res 1990;67:1405-19.

13 January CT, Wann LS, Alpert JS, et al. 2014 AHA/ACC/HRS guideline for the management of patients with atrial fibrillation: a report of the American College of Cardiology/American heart association Task force on practice guidelines and the heart rhythm Society. Circulation 2014;130:e199-267.

14 Botto GL, Politi A, Bonini W, et al. External cardioversion of atrial fibrillation: role of paddle position on technical efficacy and energy requirements. Heart 1999;82:726-30.

15 Inácio JFS, da Rosa MdosSG, Shah J, et al. Monophasic and biphasic shock for transthoracic conversion of atrial fibrillation: systematic review and network meta-analysis. Resuscitation 2016;100:66-75.

16 Kerber RE, Grayzel J, Hoyt R, et al. Transthoracic resistance in human defibrillation. Influence of body weight, chest size, serial shocks, paddle size and paddle contact pressure. Circulation 1981;63:676-82.

17 Ambler JJS, Sado DM, Zideman DA, et al. The incidence and severity of cutaneous burns following external DC cardioversion. Resuscitation 2004;61:281-8.

18 Pagan-Carlo LA, Stone MS, Kerber RE. Nature and determinants of skin "burns" after transthoracic cardioversion. Am J Cardiol 1997;79:689-91.

19 Hoke RS, Heinroth K, Trappe H-J, et al. Is external defibrillation an electric threat for bystanders? Resuscitation 2009;80:395-401.

20 Squara F, Elbaum C, Garret G, et al. Active compression versus standard anterior-posterior defibrillation for external cardioversion of atrial fibrillation: a prospective randomized study. Heart Rhythm 2021;18:360-5.

21 Warden BA, Mackay J, Jafari M, et al. Use of direct oral anticoagulants among patients undergoing cardioversion: the importance of timing before cardioversion. J Am Heart Assoc 2018;7:e010854.

22 Schmidt AS, Lauridsen KG, Torp P, et al. Maximum-fixed energy shocks for cardioverting atrial fibrillation. Eur Heart $J$ 2020;41:626-31.

23 Young M-L, Exelbert EJ, Roth T, et al. External CardioversionDefibrillation with pushing down on the chest wall to increase the success rate in obese patients. Am J Case Rep 2020;21:e927009. 